\title{
Changes of macular vessel density and thickness in gas and silicone oil tamponades after vitrectomy for macula-on rhegmatogenous retinal detachment
}

Yang Liu ${ }^{1,2,3 \dagger}$, Boya Lei ${ }^{1,2,3 \dagger}$, Rui Jiang ${ }^{1,2,3}$, Xin Huang ${ }^{1,2,3}$, Min Zhou ${ }^{1,2,3}$ and Gezhi Xu $u^{1,2,3^{*}}$

\begin{abstract}
Purpose: To investigate the macular vessel density and thickness in macular-on rhegmatogenous retinal detachment (RRD) after vitrectomy with gas and silicone oil (SO) tamponade.

Methods: Patients with macular-on RRD eyes, treated with a single successful vitrectomy with gas or SO tamponade and a minimum 30 months follow-up, were reviewed. Best-corrected visual acuity (BCVA), macular vessel density and retinal thickness by using optical coherence tomography angiography, were compared to the contralateral eyes.

Results: Sixteen eyes with gas tamponade and 17 eyes with $\mathrm{SO}$ tamponade were included in the study. LogMAR best-corrected visual acuity (BCVA) slightly improved from $0.25 \pm 0.18$ (Snellen 20/36) to $0.17 \pm 0.23$ (Snellen 20/30) in eyes with gas tamponade, and decreased from $0.30 \pm 0.22$ (Snellen 20/40) to $0.49 \pm 0.28$ (Snellen 20/62) in eyes with SO tamponade. The parafoveal vessel densities in superficial vascular complex (SVC) and the corresponding inner retinal thickness (IRT) were similar between the affected eyes and the contralateral eyes in gas tamponade group ( $P=0.578, P=0.943$ ), while significantly reduced in the affected eyes, compared to the contralateral eyes in SO tamponade group $(P<0.001, P<0.001)$.

Conclusion: Eyes in SO tamponade group had worse BCVA, lower SVC vessel densities and thinner corresponding IRT after vitrectomy for macular-on RRD, than those in gas tamponade group.

Keywords: Macular vessel density, Retinal thickness, Rhegmatogenous retinal detachment, Silicone oil tamponade, Gas tamponade
\end{abstract}

\section{Introduction}

Rhegmatogenous retinal detachment (RRD) is characterized by a full-thickness break in the neurosensory retina (NSR), variable degrees of vitreous traction, and the passage of liquefied vitreous through the break into the subretinal space. RRD requires appropriate surgery to halt

\footnotetext{
*Correspondence: 16111260005@fudan.edu.cn

†Yang Liu and Boya Lei contributed equally to this work.

${ }^{1}$ Department of Ophthalmology, Eye and ENT Hospital of Fudan University, No.83, Fen Yang Road, Shanghai 200031, China

Full list of author information is available at the end of the article
}

its progression to prevent further damage to vision. Pars plana vitrectomy (PPV) plus endotamponade is a frequent surgical option for RRD treatment. The preferred tamponades include expandable gas or silicone oil (SO) as the high surface tension and expansivity can help support the adhesions of the NSR [1,2].

Successful retinal attachment can be achieved with a tamponade; however, the SO tamponade has a reported association with unexplained vision loss [3-10]. By contrast, no similar side effects have been found in eyes with expandable gas tamponade [8]. Since the first report of original author(s) and the source, provide a link to the Creative Commons licence, and indicate if changes were made. The images or other third party material in this article are included in the article's Creative Commons licence, unless indicated otherwise in a credit line to the material. If material is not included in the article's Creative Commons licence and your intended use is not permitted by statutory regulation or exceeds the permitted use, you will need to obtain permission directly from the copyright holder. To view a copy of this licence, visit http://creativecommons.org/licenses/by/4.0/. The Creative Commons Public Domain Dedication waiver (http://creativeco mmons.org/publicdomain/zero/1.0/) applies to the data made available in this article, unless otherwise stated in a credit line to the data. 
a poorly recognized deterioration in visual acuity after SO tamponade, an increasing number of studies have focused on SO-related vision loss. In addition to loss of visual acuity, a central scotoma has been a cardinal complaint. For example, Newsom et al. were the first to objectively assess diffuse central scotoma in patients after the SO tamponade [3], and their findings were subsequently supported by the studies by Shalchi et al. and Herbert et al. $[6,11]$ A central visual dysfunction suggested a macula-limited origin, and the anatomic and electrophysiological results also provided detailed evidence to confirm a macular involvement in the pathogenetic process $[4-7,12]$.

Macular architectural changes can be detected by optical coherence tomography (OCT), while optical coherence tomography angiography (OCTA) can provide vessel details in addition to the macular retinal anatomy. Fluorangiography, thanks to the use of fluorescein, is capable of evaluating vascular hydrodynamics. OCT-A, even though it is not a dynamic evaluation (as fluorescein angiography), is able to detect vessel architecture thus evaluate the perfusion function of macular vessels. The normal scan mode can precisely reflect surface or deep capillary flow densities on the macula and precisely capture the changes in the foveal avascular zone (FAZ) [13, 14].

The aim of the present study was therefore to obtain OCTA and OCT findings in patients with macula-on primary RRD who had undergone PPV treatments, and to compare the differences in macular microvascular blood supply and thickness in cohorts administered with expandable gas versus SO tamponades. Our hypothesis was that these findings could help to account for the oddity observed in patient responses to these two tamponades.

\section{Methods}

\section{Participants and examinations}

This was a single-centered, retrospective cohort study. The medical records were reviewed for consecutively patients who had undergone vitrectomy for a primary macular-on RRD with a gas (octafluoropropane, C3F8) or SO tamponade between July 2015 and June 2017 at the Department of Ophthalmology, Eye and ENT Hospital of Fudan University.

The surgical procedures were performed with standard 23-gauge, three-port par plana vitrectomy. The central core vitreous was removed at first. Triamcinolone acetonide aqueous suspension was then applied to visualize the posterior hyaloid. The posterior vitreous and peripheral vitreous were carefully removed in sequence. Perfluorocarbon liquid was used to stabilize the floating retina if necessary. Drainage of subretinal fluid was performed with an aspiration needle under the help of perfluorocarbon liquid, air infusion, or both. After retina was internally reattached, retinal breaks were treated with laser photocoagulation through an endoprobe, with two to three rows of burns placed around each break. After air-fluid exchange, gas or SO tamponade was performed, and patients were asked to stay in a specific position according to the location of the retinal breaks.

The choice of intraocular tamponade depended on the surgeons' discretion, basically based on the degree of proliferative vitreoretinopathy (PVR) and the locations of retinal breaks. The PVR classification was based on The updated Retina Society Classification (1991) as previously described [15]. Patients with persistent retinal attachment of the affected eyes for at least 30 months after vitrectomy and with healthy contralateral eyes were included in the study. Eyes with SO tamponade would be observed for at least 3 months after vitrectomy; when attached and stable retina was observed at 3 months after vitrectomy, the patient will register and queue up for silicone oil removal. When SO-related uncontrolled elevated IOP occurred, SO removal will be arranged in advance. Silicone oil had been removed in all eyes treated with a SO tamponade when the patients were included in the study.

Patients with any of the following characteristics were excluded: 1) high myopia with axial length over $26.5 \mathrm{~mm}$ in any eye, 2) diabetes mellitus or other diseases affecting retinal blood flow, 3) anisometropia between the affected eye and contralateral eye (the difference in axial length of both eyes is more than $0.5 \mathrm{~mm}$ ), 4) preexisting ocular diseases or history of ocular trauma or surgeries, except for cataract surgery and 5) additional surgical procedures except for posterior vitreous detachment induction and posterior vitreous cortical excision were performed in macular area during vitrectomy, for example internal limiting membrane peeling.

The medical records before surgery were reviewed for both eyes of all patients. The data included best-corrected visual acuity (BCVA; in Snellen visual acuity ratios, and in logarithms of the minimum angle of resolution [logMAR] when used for the purpose of statistical analysis), intraocular pressure (IOP), axial length, and duration between symptoms and surgery.

During the follow-up, both eyes in patients with attached retinas underwent a complete ophthalmic examination, including fundus examination, BCVA, IOP, OCTA and OCT scans. The patient's blood pressure was recorded at the time of the OCTA scans, and the mean arterial pressure (MAP) was calculated as the diastolic blood pressure plus one-third of the difference between the diastolic blood pressure and the systolic blood pressure. The ocular perfusion pressure (OPP) was calculated 
by subtracting the IOP from two-thirds of the MAP [16]. An IOP of over $21 \mathrm{mmHg}$ was defined as IOP elevation.

This study was conducted in accordance with the tenets of the Declaration of Helsinki and was approved by the Institutional Review Board of the Eye and ENT Hospital of Fudan University.

\section{OCTA and OCT acquisitions}

The OCTA and OCT scans were acquired using a spectral domain OCT system (software Version 2017.1.0.155; RTVue-XR Avanti, Optovue Inc., Fremont, CA). Three dimensional (3D) OCTA scans were acquired over $3 \times 3 \mathrm{~mm}$ and $6 \times 6 \mathrm{~mm}$ areas of the macula. The image quality of all OCTA scans was assessed according to the quality index (QI) [17]. Images with QI $<6$ were excluded from the analysis. Two OCT-A scans were obtained for both eyes by a single operator during the same visit, and the average of the two measurements was calculated for statistical analysis. OCT scans were acquired for retinal thickness analysis with a retinal map protocol. The segmentation of OCT and OCTA scans were checked before analysis to avoid automatic errors. Both eyes of each participant were examined and scanned at the same visit.

\section{OCTA measurements}

An en-face retinal angiogram was generated by the RTVue-XR Avanti software, which automatically identified the projection signals from the internal limiting membrane (ILM) to the retinal pigment epithelium (RPE). Vessel density (VD) was defined as the percentage of the area occupied by vessels within the segmented area [18]. All measurements were acquired using the built-in RTVue-XR Avanti software.

The VDs in the macular areas were measured from a $6 \times 6 \mathrm{~mm}$ macular cube. The parafoveal area was defined as an annulus centered at the fovea with an inner diameter of $1 \mathrm{~mm}$ and an outer diameter of $3 \mathrm{~mm}$. The superficial vascular complex (SVC) and deep vascular complex (DVC) were analyzed separately in the macular VD analysis. The predefined boundaries provided by the Optovue software were used for the SVC and the DVC analysis. The SVC was located between the inner limiting membrane (ILM) and $10 \mu \mathrm{m}$ above the inner plexiform layer and the inner nuclear layer (IPL-INL) junction, while the DVC was located between $10 \mu \mathrm{m}$ above the IPL-INL junction and $10 \mu \mathrm{m}$ below the outer plexiform layer and outer nuclear layer (OPL-ONL) junction. The foveal avascular zone (FAZ) was measured using the software with a $3 \times 3 \mathrm{~mm}$ macular cube. The retinal en face slab (the retina from the ILM to $10 \mu \mathrm{m}$ below OPL-ONL junction) was used for the evaluation of the FAZ.

\section{Retinal thickness analyses}

Retinal thickness measurements were calculated within the parafoveal area as described before using the retinal map protocol with the built-in Avanti RTVue-XR software, as previously reported [19]. The full, inner, and outer retinal layer thicknesses (FRT, IRT, ORT) were calculated as the distance between ILM and the middle of RPE, the ILM and IPL-INL junction, and the IPLINL junction and the middle of RPE, respectively.

\section{Statistical analysis}

Data are presented as the mean \pm standard deviation. The paired-t test was used to compare the changes in the clinical variables over time or to compare clinical data between both eyes of the patient. The MannWhitney $U$ test or Fisher-Chi Square were used to compare the clinical variables in different groups. Values of $P<0.05$ were considered statistically significant. Statistical analyses were performed using SPSS for Windows Version 17.0 (SPSS Inc., Chicago, IL, USA).

\section{Results \\ Basic information}

In total, 33 patients (11 males and 22 females) with an average age of $53.5 \pm 10.0$ years (from 33 to 66 years) were enrolled in this study. They complained of decreased vision or visual-field defects for $22.0 \pm 17.7$ days (from 3 to 60 days). The mean axial length was $24.00 \pm 0.97 \mathrm{~mm}$ (from 22.42 to $26.39 \mathrm{~mm}$ ) in the affected eyes. The mean follow-up duration was $36.1 \pm 3.6$ months (from 30 to 43 months). The mean logMAR BCVA was $0.28 \pm 0.20$ (Snellen equivalent $20 / 38$, from 0.00 to 0.70 ) at presentation and $0.33 \pm 0.30$ (Snellen equivalent 20/43, from 0.00 to 1.00 ) at the last follow-up ( $P=0.348$, Paired-t test). The mean IOP was $13.1 \pm 2.6 \mathrm{mmHg}$ (from 9.50 to $19.3 \mathrm{mmHg}$ ) at presentation and $17.6 \pm 4.1 \mathrm{mmHg}$ (from 11.3 to $27.0 \mathrm{mmHg}$ ) at the last follow-up $(P<0.001$, Paired-t test).

Of the affected eyes, 16 eyes were treated with a gas tamponade and the other 17 eyes were treated with a SO tamponade. The PVR grades were similar in both groups $(P=1.000$, Fisher-Chi Square test). The extension of RRD (number of clock-hours involved) and number of retinal tears or breaks were similar in both groups $(P=0.908, P=0.685)$. The frequency of retinal breaks involving the inferior 4 clock-hours' area was higher in SO tamponade group than in gas tamponade group (4/17 eyes versus $1 / 16$ eyes), while the difference was not statistically significant $(P=0.335$, Fisher-Chi Square test). The mean duration between surgery and silicone oil removal was $5.8 \pm 2.3$ months (from 2.3 to 
Table 1 Clinical characteristics of the affected eyes

\begin{tabular}{|c|c|c|c|}
\hline & $\begin{array}{l}\text { Eyes with gas } \\
\text { tamponade }\end{array}$ & $\begin{array}{l}\text { Eyes with silicone oil } \\
\text { tamponade }\end{array}$ & $\begin{array}{l}P \text { value (Mann- } \\
\text { Whitney/Fisher-Ch } \\
\text { Square test) }\end{array}$ \\
\hline Age, years & $55.5 \pm 9.68$ & $51.5 \pm 10.1$ & 0.159 \\
\hline Sex & $4 \mathrm{M} / 12 \mathrm{~F}$ & $7 \mathrm{M} / 10 \mathrm{~F}$ & 0.465 \\
\hline Laterally & $12 \mathrm{R} / 4 \mathrm{~L}$ & $9 \mathrm{R} / 8 \mathrm{~L}$ & 0.282 \\
\hline Duration between symptoms and surgery, days & $18.2 \pm 15.9$ & $25.8 \pm 19.0$ & 0.168 \\
\hline Proliferative vitreoretinopathy grades, eyes & $\begin{array}{l}\text { PVR A\&B:8 } \\
\text { PVR C:8 }\end{array}$ & $\begin{array}{l}\text { PVR A\&B:8 } \\
\text { PVR C:9 }\end{array}$ & 1.000 \\
\hline Extension of RRD (number of clock-hours involved) & $3.7 \pm 0.9$ & $3.7 \pm 0.7$ & 0.908 \\
\hline Number of retinal tears/breaks & $1.1 \pm 0.3$ & $1.2 \pm 0.4$ & 0.685 \\
\hline $\begin{array}{l}\text { Frequency of retinal breaks involving the inferior } 4 \text { clock-hours' } \\
\text { area }\end{array}$ & $1 / 17$ & $4 / 16$ & 0.335 \\
\hline Axial length, mm & $23.9 \pm 0.8$ & $24.1 \pm 1.1$ & 0.792 \\
\hline Follow-up duration, months & $36.3 \pm 3.7$ & $35.8 \pm 3.7$ & 0.698 \\
\hline $\begin{array}{l}\text { LogMAR BCVA at presentation, } \\
\text { Snellen equivalent }\end{array}$ & $\begin{array}{l}0.25 \pm 0.18 \\
20 / 36\end{array}$ & $\begin{array}{l}0.30 \pm 0.22 \\
20 / 40\end{array}$ & 0.509 \\
\hline IOP at presentation, $\mathrm{mmHg}$ & $12.5 \pm 2.6$ & $13.6 \pm 2.5$ & 0.171 \\
\hline $\begin{array}{l}\text { LogMAR BCVA at the follow-up, } \\
\text { Snellen equivalent }\end{array}$ & $\begin{array}{l}0.17 \pm 0.23 \\
20 / 30\end{array}$ & $\begin{array}{l}0.49 \pm 0.28 \\
20 / 62\end{array}$ & $<0.001$ \\
\hline IOP at the follow-up & $16.5 \pm 3.2$ & $18.6 \pm 4.7$ & 0.191 \\
\hline
\end{tabular}

PVR Proliferative vitreoretinopathy, RRD Rhegmatogenous retinal detachment, logMAR Logarithm of the minimum angle of resolution, $B C V A$ Best corrected visual acuity, $I O P$ Intraocular pressure

13.2 months). The clinical characteristics of the affected eyes are shown in Table 1.

LogMAR BCVA in eyes tamponaded with gas slightly improved after surgery ( $P=0.300$, Paired-t test), while the value in eyes treated with SO tamponade clearly decreased ( $P=0.034$, Paired-t test). No IOP elevation was found in the gas group during the follow-up, compared with the fellow eyes. In the SO group, five of the 17 eyes (29.4\%) complained of a history of IOP elevation and all received medicine to lower the IOP. At the final visit, IOP normalized in 3 out of these 5 patients, while the remanent showed IOP elevation. Besides, four more eyes (23.5\%) presented with IOP elevation at the final visit, without the detection of symptoms before and following treatment. In conclusion, nine eyes (52.9\%) experienced with IOP elevation during follow up.

\section{Comparison of vessel density and retinal thickness between both eyes in patients receiving the gas tamponade}

For eyes treated with the gas tamponade, axial lengths were similar in the affected eyes and the contralateral healthy eyes. No statistically significant differences were found for FAZ, parafoveal VD (both SVC and DVC, Fig. 1), or retinal thickness (FRT, IRT, and ORT) between the affected and contralateral healthy eyes. The results are shown in Table 2.

\section{Comparison of vessel density and retinal thickness} between both eyes in patients receiving SO tamponade In patients who undergone SO tamponade surgery, axial lengths were similar in the affected eyes and contralateral healthy eyes. IOP was higher and the ocular perfusion pressure was lower in the affected eyes during the follow-up, with statistically significant differences. No statistically significant differences were detected for FAZ, parafoveal VD of DVC, FRT, or ORT between the affected and contralateral healthy eyes. Compared to the healthy eyes, the parafoveal VD of the SVC (Fig. 2) and IRT were reduced in the affected eyes, and the differences were all statistically significant. The results are shown in Table 3.

\section{Comparison of vessel density and retinal thickness between both eyes in patients experienced with or without IOP elevation after SO tamponade}

In the SO group, nine eyes (52.9\%) experienced with IOP elevation during follow up. For these 9 patients, the parafoveal VD of SVC, FRT and IRT were reduced in the affected eyes compared to contralateral healthy eyes, and the differences were all statistically significant. No statistically significant differences were found for the FAZ, parafoveal VD of DVC, or ORT between the affected and contralateral healthy eyes.

For the remaining eight patients that didn't experience with IOP elevation, IRT was reduced in the affected eyes 


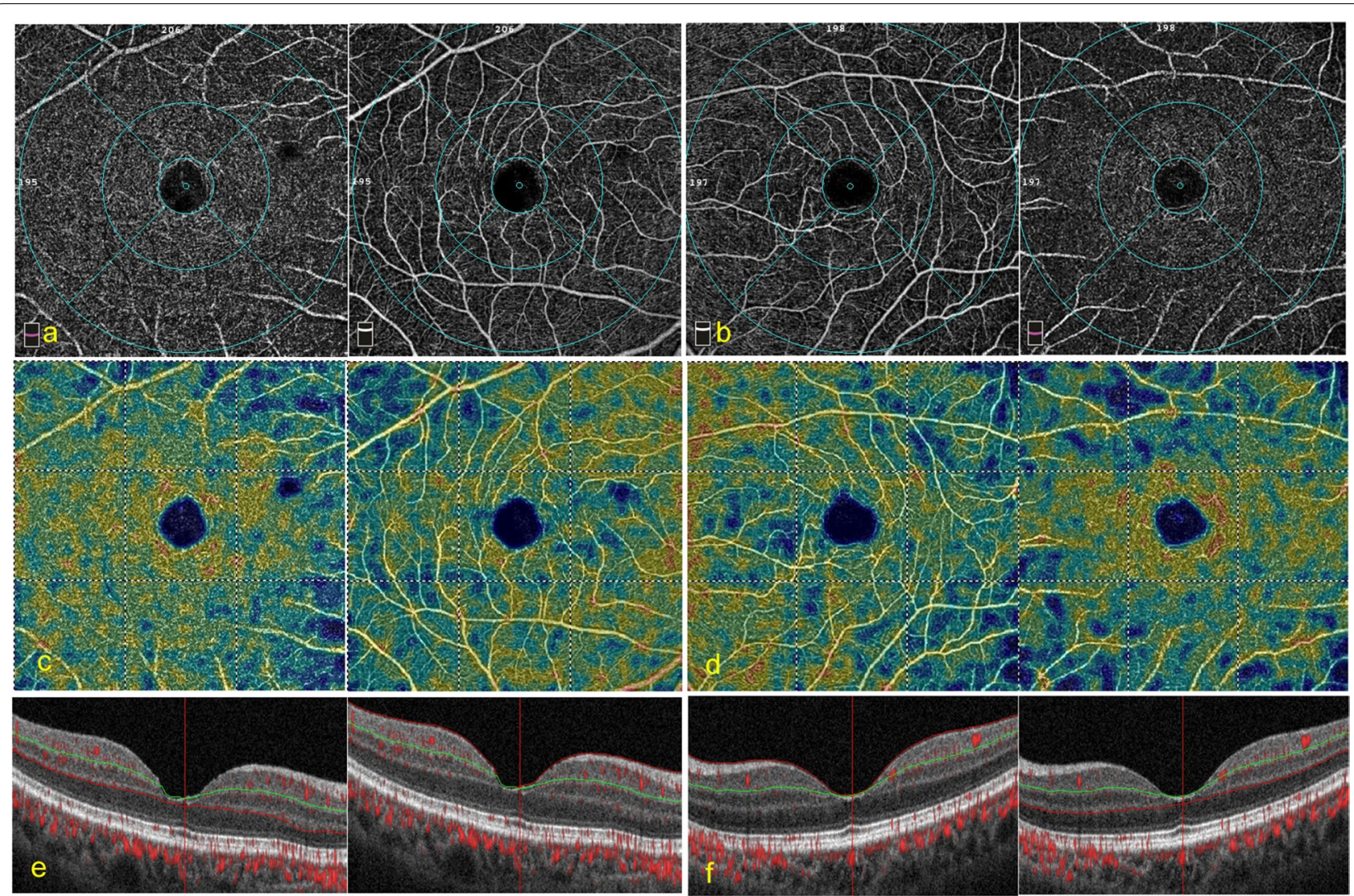

Fig. 1 A representative case of OCTA in gas tamponade eyes. A 59-year-old female patient with macula-on retinal detachment (RD) in her right eye achieved reattachment in one shot. The preoperative best-corrected visual acuity (BCVA) was LogMAR 0.3 (Snellen equivalent 20/40). The intraocular pressure (IOP) was $10 \mathrm{mmHg}$. Postoperatively, BCVA increased to LogMAR 0.1 (Snellen equivalent 20/25), the IOP was $14 \mathrm{mmHg}$, with no history of IOP elevation. No significant difference of vessel density (VD) was found in the affected and contralateral eyes. $\mathbf{a}$ the $6 \times 6 \mathrm{~mm}$ en face angiogram in the affected eye: left: the deep vessel complex (DVC); right: the superficial vessel complex (SVC); $\mathbf{b}$ the $6 \times 6 \mathrm{~mm}$ en face angiogram in the contralateral eye: left: the SVC; right: the DVC; $\mathbf{c}$ the $6 \times 6 \mathrm{~mm}$ false coloring angiogram in the affected eye: left: the DVC; right: the SVC; $\mathbf{d}$ the $6 \times 6 \mathrm{~mm}$ false coloring angiogram in the contralateral eye: left: the SVC; right: the DVC; e the OCT B scan image with layered boundary details in the affected eye: left: the DVC; right: the SVC; $\mathbf{f}$ the OCT B scan image with layered boundary details in contralateral eye: left: the SVC; right: the DVC

Table 2 Comparison of vessel density and retinal thickness between both eyes in patients receiving the gas tamponade

\begin{tabular}{llll}
\hline & The affected eyes & The healthy eyes & $P($ Paired-t) \\
\hline Axial length, mm & $23.92 \pm 0.75$ & $24.11 \pm 1.21$ & 0.372 \\
logMAR BCVA at presentation, & $0.25 \pm 0.18$ & $0.07 \pm 0.10$ & $\mathbf{0 . 0 0 1}$ \\
Snellen equivalent & $20 / 36$ & $20 / 23$ & $13.8 \pm 2.8$ \\
IOP at presentation, mmHg & $12.5 \pm 2.6$ & $0.06 \pm 0.09$ & $\mathbf{0 . 0 1 0}$ \\
logMAR BCVA at follow up, & $0.17 \pm 0.23$ & $20 / 23$ & $\mathbf{0 . 0 2 0}$ \\
Snellen equivalent & $20 / 30$ & $15.1 \pm 2.0$ & 0.103 \\
IOP at follow up & $16.5 \pm 3.2$ & $50.61 \pm 6.31$ & 0.103 \\
Ocular perfusion pressure at follow up, mmHg & $49.20 \pm 6.41$ & $0.315 \pm 0.111$ & 0.693 \\
FAZ, mm ${ }^{2}$ & $0.304 \pm 0.179$ & $43.17 \pm 4.30$ & 0.578 \\
Parafoveal VD of SVC (\%) & $44.13 \pm 4.90$ & $52.59 \pm 4.36$ & 0.120 \\
Parafoveal VD of DVC (\%) & $50.24 \pm 4.34$ & $313.19 \pm 11.17$ & 0.294 \\
Full retinal thickness, $\mu \mathrm{m}$ & $319.13 \pm 23.23$ & $122.06 \pm 7.52$ & 0.943 \\
Inner retinal thickness, $\mu \mathrm{m}$ & $121.75 \pm 15.97$ & $190.81 \pm 8.26$ & 0.075 \\
Outer retinal thickness, $\mu \mathrm{m}$ & $195.44 \pm 13.47$ & &
\end{tabular}

IogMAR Logarithm of the minimum angle of resolution, BCVA Best corrected visual acuity, IOP Intraocular pressure, FAZ Foveal avascular zone, VD Vessel density, SVC Superior vascular complex, DVC Deep vascular complex 


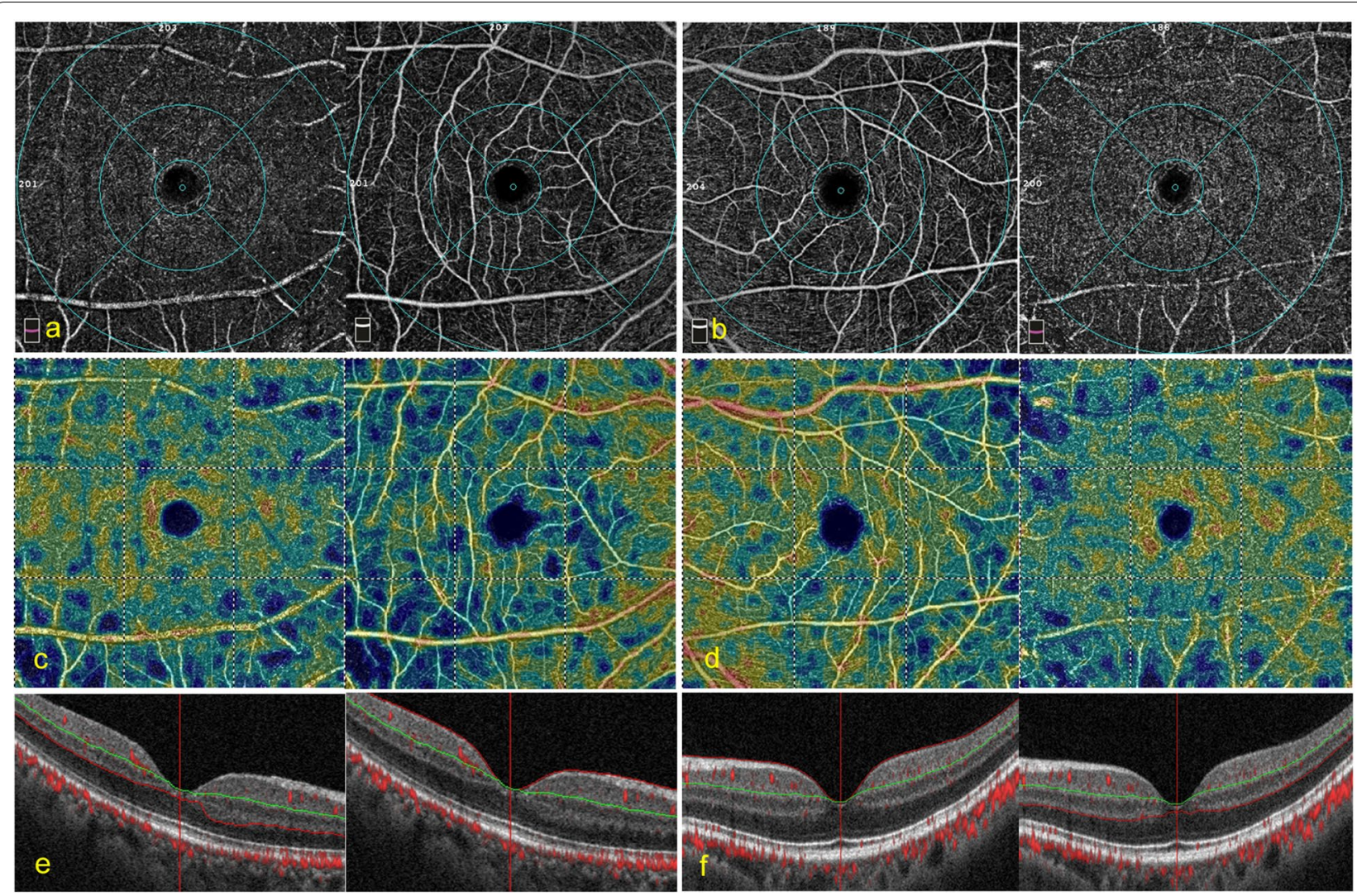

Fig. 2 A representative case of OCTA in silicone oil (SO) tamponade eyes. A 53-year-old female patient with macula-on RRD in her right eye achieved reattachment in one shot. The period for SO in suit lasted for 4.5 months. The preoperative best-corrected visual acuity (BCVA) was LogMAR 0.22 (Snellen equivalent 20/33). The intraocular pressure (IOP) was $13 \mathrm{mmHg}$. Postoperatively, the BCVA decreased to LogMAR 0.52 (Snellen equivalent 20/67), the IOP was $19 \mathrm{mmHg}$. The patient complaint of a history of IOP elevation, with a limit high to $32 \mathrm{mmHg}$ for 2 weeks. A significantly decreased parafoveal vessel density (VD) of superficial vessel complex was found in the affected eye, compared with the fellow eye. a the $6 \times 6 \mathrm{~mm}$ en face angiogram in the affected eye: left: the deep vessel complex (DVC); right: the superficial vessel complex (SVC); $\mathbf{b}$ the $6 \times 6 \mathrm{~mm}$ en face angiogram in the contralateral eye: left: the SVC; right: the DVC; $\mathbf{c}$ the $6 \times 6 \mathrm{~mm}$ false coloring angiogram in the affected eye: left: the DVC; right: the SVC; $\mathbf{d}$ the $6 \times 6 \mathrm{~mm}$ false coloring angiogram in the contralateral eye: left: the SVC; right: the DVC; e the OCT B scan image with layered boundary details in the affected eye: left: the DVC; right: the SVC; $\mathbf{f}$ the OCT B scan image with layered boundary details in the contralateral eye: left: the SVC; right: the DVC

compared to contralateral healthy eyes with statistically significant difference. While no statistically significant differences were found for the FAZ, parafoveal VD of SVC and DVC, FRT, or ORT between the affected and contralateral healthy eyes. Results are shown in Table 4.

\section{Discussion}

In the present study, the parafoveal VD of macular-on RRD eyes were investigated after successful retinal reattachment with a gas or SO tamponade. In the gas group, no statistically significant differences were found in FAZ, parafoveal VD of SVC and DVC between the affected eyes and the contralateral healthy eyes, in agreement with previous work [20, 21]. However, in Bonfiglio's study, they found a lower mean DVC in the parafoveal subfield, in disagreement with our results [22]. The difference may partly come from the relatively larger RRD extension in their work ( $2.0 \pm 0.8$ quadrants). For the macular microcirculation was proved to be disturbed in macula-on RRD patients, and correlated with the extent of the retinal detachment [23]. It was possible that the baseline macular perfusion was more influenced in their cohort. For another, they followed up for at least 12 months, shorter than our 33 months. Macular microcirculation in DVC may experience recovery following successful RRD repair [24]. A longer observation period makes it easier to see the reestablishment of macular microcirculation. In the SO group, the parafoveal VD of SVC was reduced in the affected eyes compared to the healthy eyes, in agreement with previous findings by $\mathrm{Ma}$ [25], who postulated that maintenance of a prone position during SO tamponade may cause mechanical compression to the SVC, leading to ischemia. It is known that 
Table 3 Comparison of vessel density and retinal thickness between both eyes in patients receiving the silicone oil tamponade

\begin{tabular}{|c|c|c|c|}
\hline & Affected eye & Healthy eye & $P($ Paired-t) \\
\hline Axial length, mm & $24.1 \pm 1.1$ & $24.0 \pm 1.1$ & 0.199 \\
\hline $\begin{array}{l}\text { logMAR BCVA at presenta- } \\
\text { tion, } \\
\text { Snellen equivalent }\end{array}$ & $\begin{array}{l}0.30 \pm 0.22 \\
20 / 40\end{array}$ & $\begin{array}{l}0.06 \pm 0.15 \\
20 / 23\end{array}$ & 0.001 \\
\hline $\begin{array}{l}\text { IOP at presentation, } \\
\mathrm{mmHg}\end{array}$ & $12.6 \pm 2.5$ & $15.5 \pm 2.0$ & 0.001 \\
\hline $\begin{array}{l}\text { logMAR BCVA at follow } \\
\text { up, } \\
\text { Snellen equivalent }\end{array}$ & $\begin{array}{l}0.49 \pm 0.28 \\
20 / 62\end{array}$ & $\begin{array}{l}0.02 \pm 0.06 \\
20 / 21\end{array}$ & $<0.001$ \\
\hline IOP at follow up & $18.6 \pm 4.7$ & $16.4 \pm 3.4$ & 0.006 \\
\hline $\begin{array}{l}\text { Ocular perfusion pressure } \\
\text { at follow up, } \mathrm{mmHg}\end{array}$ & $41.0 \pm 7.8$ & $43.2 \pm 6.8$ & 0.006 \\
\hline $\mathrm{FAZ}, \mathrm{mm}^{2}$ & $0.267 \pm 0.110$ & $0.339 \pm 0.088$ & 0.061 \\
\hline Parafoveal VD of SVC (\%) & $39.26 \pm 3.54$ & $45.46 \pm 4.08$ & $<0.001$ \\
\hline Parafoveal VD of DVC (\%) & $51.16 \pm 5.08$ & $51.57 \pm 4.13$ & 0.807 \\
\hline Full retinal thickness, $\mu \mathrm{m}$ & $295.25 \pm 27.68$ & $311.00 \pm 29.69$ & 0.120 \\
\hline Inner retinal thickness, $\mu \mathrm{m}$ & $107.94 \pm 15.21$ & $128.38 \pm 11.06$ & $<0.001$ \\
\hline $\begin{array}{l}\text { Outer retinal thickness, } \\
\mu \mathrm{m}\end{array}$ & $187.13 \pm 15.25$ & $191.13 \pm 6.68$ & 0.401 \\
\hline
\end{tabular}

$\log M A R$ Logarithm of the minimum angle of resolution, $B C V A$ Best corrected visual acuity, IOP Intraocular pressure, FAZ Foveal avascular zone, VD Vessel density, SVC Superior vascular complex, DVC Deep vascular complex

post-operation body position was mainly dependent on the location of the retinal breaks. The prone position was one of the primary choices [26]. Now, the body position requirements are rather flexible: patients were permitted to adjust their body based on doctors' advice, like prone, upright, sitting or a recumbent lateral positioning, ensuring the rehabilitation first, at the same time, beneficial to decrease discomfort and increase compliance [27]. Under such circumstances, the effect of mechanical stress caused by the prone position seemed to be limited, the macula did not suffer from the buoyancy force of the $\mathrm{SO}$ all the time. The causes of SVC-VD changes may lie on some other aspects.

The blood supply to the superficial retina is associated with the ganglion cell complex, including the retinal nerve fiber layer (RNFL), retinal ganglion cells (RGCs), and IPL. Given the special geographic location of the SVC, a decrease in SVC-VD is more frequently discussed in the context of glaucoma. The systematic review by Flammer et al. in 2002 noted the common finding in a majority of studies that the retinal circulation was reduced in glaucomatous eyes [28]. Recently, more vascular flow details have been depicted using OCTA. The glaucomatous eyes show a lower macular VD, which preferentially affects the SVC rather than the DVC [29]. The changes related to superficial vessel perfusion that occur in glaucoma arise in part from the elevation of IOP, as confirmed by in-vivo tests [30]. The increased IOP appeared to be an unavoidable adverse event in the SO tamponade eyes [31]. Previous reports indicate that the incidence varies in a widely fluctuating range, even as high as $50 \%$. In our study, nine eyes $(52.9 \%)$ once experienced with IOP elevation during follow up, while no IOP elevation was observed in the gas group.

The IOP elevation may occur in acute or chronic form with SO tamponade. The acute manifestations, like the pupillary block or migration of $\mathrm{SO}$, is prone to be found and controlled. However, the chronic IOP elevation in the mid-late phase, caused by SO emulsification, seemed to be more easily neglected. The process developed even after SO removal, which made it hard to be sensed and timely remedied [31]. The emulsification microglobules are considered to mechanically obstruct the trabecular meshwork or to be toxic to the outflow apparatus, thus inducing a rise in IOP [32]. Ultrastructural evidence has shown the presence of $\mathrm{SO}$ in the trabecular meshwork

Table 4 Comparison of vessel density and retinal thickness between both eyes in patients experienced with or without intraocular pressure elevation after silicone oil tamponade

\begin{tabular}{|c|c|c|c|c|c|c|}
\hline \multirow[t]{2}{*}{ SO tamponade } & \multicolumn{3}{|c|}{ Patients with IOP elevation } & \multicolumn{3}{|c|}{ Patients without IOP elevation } \\
\hline & Affected eye & Healthy eye & $P$ (Paired-t) & Affected eye & Healthy eye & $P$ (Paired-t) \\
\hline $\begin{array}{l}\text { logMAR BCVA at follow up, } \\
\text { Snellen equivalent }\end{array}$ & $0.48 \pm 0.26$ & $0.01 \pm 0.06$ & 0.001 & $0.50 \pm 0.33$ & $0.04 \pm 0.05$ & 0.005 \\
\hline $\mathrm{FAZ}, \mathrm{mm}^{2}$ & $0.221 \pm 0.090$ & $0.347 \pm 0.100$ & 0.052 & $0.319 \pm 0.111$ & $0.331 \pm 0.077$ & 0.757 \\
\hline Parafoveal VD of SVC (\%) & $38.69 \pm 3.19$ & $46.26 \pm 2.32$ & $<0.001$ & $39.91 \pm 4.01$ & $44.55 \pm 5.48$ & 0.079 \\
\hline Parafoveal VD of DVC (\%) & $50.10 \pm 4.80$ & $51.76 \pm 4.95$ & 0.482 & $52.34 \pm 5.43$ & $51.36 \pm 3.31$ & 0.716 \\
\hline Full retinal thickness, $\mu \mathrm{m}$ & $290.33 \pm 26.95$ & $316.22 \pm 13.08$ & 0.022 & $305.63 \pm 29.53$ & $305.13 \pm 40.24$ & 0.976 \\
\hline Inner retinal thickness, $\mu \mathrm{m}$ & $106.89 \pm 13.66$ & $128.89 \pm 13.31$ & 0.013 & $112.50 \pm 19.02$ & $127.88 \pm 7.70$ & 0.025 \\
\hline Outer retinal thickness, $\mu \mathrm{m}$ & $183.33 \pm 15.94$ & $191.33 \pm 8.82$ & 0.286 & $192.88 \pm 13.12$ & $189.63 \pm 4.34$ & 0.555 \\
\hline
\end{tabular}

SO Silicone oil, IOP Intraocular pressure, logMAR Logarithm of the minimum angle of resolution, BCVA Best corrected visual acuity, VD Vessel density, SVC Superior vascular complex, DVC Deep vascular complex 
of enucleated eyes [33]. Immunohistochemical samples have also revealed a macrophage response associated with oil in the meshwork. Chan et al. tested the aqueous washouts after $\mathrm{SO}$ removal and found that more than $95 \%$ of the SO droplets in the non-clinical emulsification samples had a diameter smaller than those detectable by slit-lamp biomicroscopy $(7 \mu \mathrm{m})$ [34].

A sub-analysis in the SO group showed that in patients suffering from IOP elevation, a lower parafoveal VD of SVC was found in the affected eyes compared with contralateral healthy eyes, while this phenomenon was not observed in patients without IOP elevation after SO tamponade. This implied that changes in IOP might participate in the process of superficial vessel perfusion loss in eyes with $\mathrm{SO}$ tamponade.

Besides, we observed the retinal thickness in different tamponade groups. The SO tamponade eyes showed a significantly reduced IRT compared with the contralateral healthy eyes, whereas no similar changes were detected in the gas group. The thinning of IRT, on one hand, may be induced by IOP elevation in SO tamponade eyes, as shown in glaucomatous group [35], however, in SO group sub analysis, a thinner IRT was also observed in the affected eyes of patients without IOP elevation. This indicates that some other aspects might exist to induce the changes in IRT, independent of IOP changes. The toxicity of SO to the retinal neurons might be an explanation and had been widely discussed [11, 36, 37]. The inner retina is in direct contact with SO, and experimental evidence in vitro has shown that emulsified SO can be taken up by primary retinal microglia, where it induces a pro-inflammatory response [38]. Studies with enucleated eyes applied with SO tamponade confirmed that intraretinal macrophages contained phagocytosed $\mathrm{SO}$, and the eccentric pigment granules were present in the superficial retina [34]. These findings raised the speculation that a secondary inflammation related to SO itself may take part in the regional retinal injury. In our study, the affected region involves the para-fovea, a site with a high density of RGCs, which implies that RGCs are sensitive to SO contact [39]. The toxicity on the RGCs might directly influence the IRT in the SO group observed in the present study, as a result of retinal injury.

Unexplained vision loss in SO tamponade eyes after macula-on RRD surgery has been discussed in many studies [5-9]. The decreased parafoveal VD of SVC and IRT observed in the present study, which might be related to IOP elevation and SO toxicity, provides us with some ideas that might explain this phenomenon. A recent retrospective report speculated IOP elevation during SO tamponade to be the most important risk factor for vision loss [9]. In another SO tamponade cohort, 10 of 11 eyes with unexplained visual loss were found to experience with IOP elevation [8]. Similar central visual field changes have been observed in eyes with early glaucoma [40]. Furthermore, OCT examinations have presented with either a central foveal atrophy or a thickening in SO tamponade eyes, but the macular thinning was more likely to occur over long-term observation [5-8, 41]. Along with the image pixel enhancement, the thinning slabs were limited to the IRT, suggestive of injury to the innermost neuronal cells $[5,6,8]$. In consideration of these findings, the SO related perfusion-related damage and direct toxicity to macular neurons were hypothesized to lead to the subsequent vision dysfunction.

The strengths of the present study are its relatively long follow-up and its comparison with different tamponade cohorts. Only macula-sparing RRD was included in the two groups, which prevented the bias of macular flow density effects due to regional retinal detachment. However, the inherent retrospective nature and the small sample size precluded any further discovery of the potential causality in the changes in BCVA, IRT, SVC-VD, and IOP. It is more promising if we could record the dynamic changes of the indicators above during the follow-up. Further understanding of the macular visual defects occurring in $\mathrm{SO}$ tamponade eyes will require more macular function examinations, like microperimetry or contrast sensitivity, to identify the underlying mechanism. In addition, concerns on the optic nerve may provide new insights to explain the vision changes caused by SO.

\section{Conclusion}

In this article, we retrospectively applied OCTA and OCT to disclose the macular vascular density and thickness details in macula-on RRD after surgery, and compared BCVA, parafoveal vessel density, and retinal thickness in gas and SO tamponade groups. Although experienced with the same surgical procedure, the $\mathrm{SO}$ group had a worse BCVA, lower parafoveal VD of SVC, and a thinner IRT. For this reason, the gas tamponade may be a better treatment choice in the long run for suitable patients with macula-on RRD.

\section{Abbreviations}

RRD: Rhegmatogenous retinal detachment; SO: Silicone oil; OCTA: Optical coherent tomographic angigraphy; OCT: Optical coherent tomography; SVC: Superficial vascular complex; IRT: Inner retinal thickness.

\section{Acknowledgments}

The authors thank Yanqiong Zhang, Dekang Gan, Ling Wang and Xiaogang Luo (Eye and ENT Hospital of Fudan University) for their contributions to data collection.

\section{Authors' contributions}

Y.L., BY.L, R.J., X.H., and M.Z. participated in the collection of clinical information. Y.L. and BY.L. reviewed the literature and drafted the manuscript. GZ.X. designed the study and critically revised the article. All authors gave final approval of the version to be published. 


\section{Funding}

This work was supported by the Shanghai Clinical Three-Year Action PlanMajor Clinical Research Project (SHDC2020CR2041B), Xuhui District Health and Family Planning Commission Key Disease Joint Project (XHLHGG201807).

\section{Availability of data and materials}

Most of data generated or analyzed during this study have disclosed in this article. The remaining datasets are available upon reasonable request from the corresponding author.

\section{Declarations}

\section{Ethics approval and consent to participate}

This study followed the rules Declaration of Helsinki and was approved by the Institutional Review Board of the Eye and ENT Hospital of Fudan University. The reference number is 2014043. Written informed consent was obtained from the all patients.

\section{Consent for publication}

All the patients included in this study gave written consent for their personal or clinical details to be published in this study.

\section{Competing interests}

The authors have no conflicts of interest to declare.

\section{Author details}

1'Department of Ophthalmology, Eye and ENT Hospital of Fudan University, No.83, Fen Yang Road, Shanghai 200031, China. ${ }^{2}$ Shanghai Key Laboratory of Visual Impairment and Restoration, Fudan University, Shanghai, China. ${ }^{3}$ Key Laboratory of Myopia of State Health Ministry, Fudan University, Shanghai, China.

Received: 23 April 2021 Accepted: 30 October 2021

Published online: 15 November 2021

\section{References}

1. Riedel KG, Gabel VP, Neubauer L, Kampik A, Lund OE. Intravitreal silicone oil injection: complications and treatment of 415 consecutive patients. Graefes Arch Clin Exp Ophthalmol. 1990;228(1):19-23. https://doi.org/10. 1007/bf02764284.

2. Angunawela Rl, Azarbadegan A, Aylward GW, Eames I. Intraocular fluid dynamics and retinal shear stress after vitrectomy and gas tamponade. Invest Ophthalmol Vis Sci. 2011;52(10):7046-51. https://doi.org/10.1167/ iovs.10-6872.

3. Newsom RSB, Johnston R, Sullivan PM, Aylward GB, Holder GE, Gregor ZJ. Sudden visual loss after removal of silicone oil. Retina (Philadelphia, Pa.). 2004;24(6):871-7. https://doi.org/10.1097/00006982-200412000-00005.

4. Cazabon S, Groenewald C, Pearce IA, Wong D. Visual loss following removal of intraocular silicone oil. Br J Ophthalmol. 2005;89(7):799-802. https://doi.org/10.1136/bjo.2004.053561

5. Christensen UC, la Cour M. Visual loss after use of intraocular silicone oil associated with thinning of inner retinal layers. Acta Ophthalmol. 2012:90(8):733-7. https://doi.org/10.1111/j.1755-3768.2011.02248.x.

6. Shalchi Z, Mahroo OA, Shunmugam M, Mohamed M, Sullivan PM, Williamson TH. Spectral domain optical coherence tomography findings in long-term silicone oil-related visual loss. Retina (Philadelphia, Pa.). 2015;35(3):555-63. https://doi.org/10.1097/iae.0000000000000325.

7. Tode J, Purtskhvanidze K, Oppermann T, Hillenkamp J, Treumer F, Roider J. Vision loss under silicone oil tamponade. Graefes Arch Clin Exp Ophthalmol. 2016;254(8):1465-71. https://doi.org/10.1007/s00417-016-3405-z.

8. Scheerlinck LM, Schellekens PA, Liem AT, Steijns D, Leeuwen R. Incidence, risk factors, and clinical characteristics of unexplained visual loss after intraocular silicone oil for macula-on retinal detachment. Retina. 2016:36(2):342-50. https://doi.org/10.1097/iae.0000000000000711.

9. Marti M, Walton R, Böni C, Zweifel SA, Stahel M, Barthelmes D. Increased intraocular pressure is a risk factor for unexplained visual loss during silicone oil endotamponade. Retina (Philadelphia, Pa.). 2017;37(12):2334-40. https://doi.org/10.1097/iae.0000000000001492.
10. Morphis G, Irigoyen C, Eleuteri A, Stappler T, Pearce I, Heimann H. Retrospective review of 50 eyes with long-term silicone oil tamponade for more than 12 months. Graefes Arch Clin Exp Ophthalmol. 2012;250(5):645-52. https://doi.org/10.1007/s00417-011-1873-8.

11. Herbert EN, Habib M, Steel D, Williamson TH. Central scotoma associated with intraocular silicone oil tamponade develops before oil removal. Graefes Arch Clin Exp Ophthalmol. 2006;244(2):248-52. https://doi.org/ 10.1007/s00417-005-0076-6.

12. Feng X, Li C, Zheng Q, Qian XG, Shao W, Li Y, et al. Risk of silicone oil as vitreous tamponade in pars plana vitrectomy: a systematic review and meta-analysis. Retina. 2017;37(11):1989-2000. https://doi.org/10.1097/ IAE.0000000000001553.

13. Spaide RF, Fujimoto JG, Waheed NK, Sadda SR, Staurenghi G. Optical coherence tomography angiography. Prog Retin Eye Res. 2018;64:1-55. https://doi.org/10.1016/j.preteyeres.2017.11.003.

14. Christou EE, Stavrakas P, Batsos G, Christodoulou E, Stefaniotou M. Association of OCT-A characteristics with postoperative visual acuity after rhegmatogenous retinal detachment surgery: a review of the literature. Int Ophthalmol. 2021;41(6):2283-92. https://doi.org/10.1007/ s10792-021-01777-2.

15. Machemer R, Aaberg TM, Freeman HM, Irvine AR, Lean JS, Michels RM. An updated classification of retinal detachment with proliferative vitreoretinopathy. Am J Ophthalmol. 1991;112(2):159-65. https://doi.org/10.1016/ s0002-9394(14)76695-4.

16. Yu J, Jiang $C$, Wang $X$, Zhu L, Gu R, Xu H, et al. Macular perfusion in healthy Chinese: an optical coherence tomography angiogram study. Invest Ophthalmol Vis Sci. 2015;56(5):3212-7. https://doi.org/10.1167/ iovs.14-16270.

17. Lavia C, Couturier A, Erginay A, Dupas B, Tadayoni R, Gaudric A. Reduced vessel density in the superficial and deep plexuses in diabetic retinopathy is associated with structural changes in corresponding retinal layers. PLoS One. 2019;14(7):e219164. https://doi.org/10.1371/journal.pone. 0219164.

18. Jia Y, Morrison JC, Tokayer J, Tan O, Lombardi L, Baumann B, et al. Quantitative OCT angiography of optic nerve head blood flow. Biomed Opt Express. 2012;3(12):3127-37. https://doi.org/10.1364/boe.3.003127.

19. $X u H, Y u J$, Kong $X$, Sun $X$, Jiang C. Macular microvasculature alterations in patients with primary open-angle glaucoma: a cross-sectional study. Medicine (Baltimore). 2016;95(33):e4341. https://doi.org/10.1097/MD. 0000000000004341

20. Yoshikawa Y, Shoji T, Kanno J, Ibuki H, Ozaki K, Ishii H, et al. Evaluation of microvascular changes in the macular area of eyes with rhegmatogenous retinal detachment without macular involvement using sweptsource optical coherence tomography angiography. Clin Ophthalmol. 2018;12:2059-67. https://doi.org/10.2147/opth.s177933.

21. Hong $\mathrm{EH}, \mathrm{Cho} H$, Kim DR, Kang MH, Shin YU, Seong M. Changes in retinal vessel and retinal layer thickness after vitrectomy in retinal detachment via swept-source OCT angiography. Invest Ophthalmol Vis Sci. 2020:61(2):35. https://doi.org/10.1167/iovs.61.2.35.

22. Bonfiglio V, Ortisi E, Scollo D, Reibaldi M, Russo A, Pizzo A, et al. Vascular changes after vitrectomy for rhegmatogenous retinal detachment: optical coherence tomography angiography study. Acta Ophthalmol. 2019. https:/doi.org/10.1111/aos.14315.

23. Eshita T, Shinoda K, Kimura I, Kitamura S, Ishida S, Inoue M, et al. Retinal blood flow in the macular area before and after scleral buckling procedures for Rhegmatogenous retinal detachment without macular involvement. Jpn J Ophthalmol. 2004;48(4):358-63. https://doi.org/10.1007/ s10384-004-0096-5.

24. Woo JM, Yoon YS, Woo JE, Min JK. Foveal avascular zone area changes analyzed using OCT angiography after successful Rhegmatogenous retinal detachment repair. Curr Eye Res. 2018;43(5):674-8. https://doi.org/ 10.1080/02713683.2018.1437922.

25. Ma Y, Zhu XQ, Peng XY. Macular perfusion changes and ganglion cell complex loss in patients with silicone oil-related visual loss. Biomed Environ Sci. 2020;33(3):151-7. https://doi.org/10.3967/bes2020.021.

26. Goldbaum MH, McCuen BW, Hanneken AM, Burgess SK, Chen HH. Silicone oil tamponade to seal macular holes without position restrictions. Ophthalmology. 1998;105(11):2140-7 2147-48.

27. Chen $X$, Yan Y, Hong L, Zhu L. A comparison of strict face-down positioning with adjustable positioning after pars plana vitrectomy 
and gas tamponade for rhegmatogenous retinal detachment. Retina. 2015;35(5):892-8. https://doi.org/10.1016/s0161-6420(98)91140-x.

28. Flammer J, Orgül S, Costa VP, Orzalesi N, Krieglstein GK, Serra LM, et al. The impact of ocular blood flow in glaucoma. Prog Retin Eye Res. 2002;21(4):359-93. https://doi.org/10.1016/s1350-9462(02)00008-3.

29. Takusagawa HL, Liu L, Ma KN, Jia Y, Gao SS, Zhang M, et al. Projectionresolved optical coherence tomography angiography of macular retinal circulation in glaucoma. Ophthalmology. 2017;124(11):1589-99. https:// doi.org/10.1016/j.ophtha.2017.06.002.

30. Zhao D, He Z, Wang L, Fortune B, Lim JKH, Wong VHY, et al. Response of the Trilaminar retinal vessel network to intraocular pressure elevation in rat eyes. Invest Ophth Vis Sci. 2020;61 (2):2. https://doi.org/10.1167/iovs. 61.2.2.

31. Ichhpujani P, Jindal A, Jay Katz L. Silicone oil induced glaucoma: a review. Graefes Arch Clin Exp Ophthalmol. 2009;247(12):1585-93. https://doi.org/ 10.1007/s00417-009-1155-x.

32. Avitabile T, Bonfiglio V, Cicero A, Torrisi B, Reibaldi A. Correlation between quantity of silicone oil emulsified in the anterior chamber and high pressure in vitrectomized eyes. Retina (Philadelphia, Pa). 2002;22(4):443-8. https://doi.org/10.1097/00006982-200208000-00008.

33. Wickham L, Asaria RH, Alexander R, Luthert P, Charteris DG. Immunopathology of intraocular silicone oil: enucleated eyes. Brit J Ophthalmol. 2007;91(2):253-7. https://doi.org/10.1136/bjo.2006.103564.

34. Chan YK, Cheung N, Chan WSC, Wong D. Quantifying silicone oil emulsification in patients: are we only seeing the tip of the iceberg? Graefes Arch Clin Exp Ophthalmol. 2015;253(10):1671-5. https://doi.org/10.1007/ s00417-014-2866-1.

35. Tan O, Chopra V, Lu AT, Schuman JS, Ishikawa H, Wollstein G, et al. Detection of macular ganglion cell loss in glaucoma by Fourier-domain optical coherence tomography. Ophthalmology. 2009;116(12):2305-14. https:// doi.org/10.1016/j.ophtha.2009.05.025.

36. Yamada K, Kaneko H, Tsunekawa T, Shimizu H, Suzumura A, Namba R, et al. Silicone oil-associated retinal light exposure under a surgical microscope. Acta Ophthalmol. 2019;97(5):e742-6. https://doi.org/10.1111/aos. 14038.

37. Scheerlinck LM, Kuiper JJ, Liem AT, Schellekens PA, van Leeuwen R. Electrolyte composition of retro-oil fluid and silicone oil-related visual loss. Acta Ophthalmol. 2016;94(5):449-53. https://doi.org/10.1111/aos.12959.

38. Klettner A, Harms A, Waetzig V, Tode J, Purtskhvanidze K, Roider J. Emulsified silicone oil is taken up by and induces pro-inflammatory response in primary retinal microglia. Graefes Arch Clin Exp Ophthalmol. 2020;258(9):1965-74. https://doi.org/10.1007/s00417-020-04763-z.

39. Yu DY, Yu PK, Cringle SJ, Kang MH, Su EN. Functional and morphological characteristics of the retinal and choroidal vasculature. Prog Retin Eye Res. 2014;40:53-93. https://doi.org/10.1016/j.preteyeres.2014.02.001

40. Traynis I, De Moraes CG, Raza AS, Liebmann JM, Ritch R, Hood DC. Prevalence and Nature of Early Glaucomatous Defects in the Central $10^{\circ}$ of the Visual Field. JAMA Ophthalmol. 2014;132(3):291. https://doi.org/10.1001/ jamaophthalmol.2013.7656

41. Caramoy A, Droege KM, Kirchhof B, Fauser S. Retinal layers measurements in healthy healthy eyes and in eyes receiving silicone oil-based endotamponade. Acta Ophthalmol. 2014;92(4):e292-7. https://doi.org/10.1111/ aos.12307.

\section{Publisher's Note}

Springer Nature remains neutral with regard to jurisdictional claims in published maps and institutional affiliations.
Ready to submit your research? Choose BMC and benefit from:

- fast, convenient online submission

- thorough peer review by experienced researchers in your field

- rapid publication on acceptance

- support for research data, including large and complex data types

- gold Open Access which fosters wider collaboration and increased citations

- maximum visibility for your research: over 100M website views per year

At BMC, research is always in progress.

Learn more biomedcentral.com/submissions 